\title{
Correlates of Quality of Life in Anxiety Disorders: Review of Recent Research
}

\author{
M. Taylor Wilmer ${ }^{1}\left[\right.$ C $\cdot$ Kelley Anderson ${ }^{1} \cdot$ Monique Reynolds $^{1}$
}

Accepted: 24 August 2021 / Published online: 6 October 2021

(c) The Author(s), under exclusive licence to Springer Science+Business Media, LLC, part of Springer Nature 2021

\begin{abstract}
Purpose of Review Anxiety disorders are highly prevalent conditions that have a detrimental impact on quality of life (QOL), particularly when left untreated. In the present review, we summarize recent literature, published within the last 3 years, on QOL in anxiety disorders, with a focus on factors that may play a role in the relationship between anxiety and QOL.

Recent Findings We organize our findings into four categories: (1) subjective distress, (2) behavioral responses, (3) functional impairment, and (4) clinical factors. Results indicate that greater anxiety symptom severity is linked with poorer QOL, and cognitive behavioral therapies for anxiety yield positive effects on QOL. Additional transdiagnostic mechanisms are highlighted, including anxiety sensitivity, distress tolerance, emotion regulation, and avoidant coping. We examine the role of functional impairment, and we discuss factors related to treatment, including comorbidity and longitudinal effects. We also consider early research from the COVID-19 pandemic.

Summary Understanding the underlying factors that contribute to QOL detriments provides important insight into the impact of anxiety disorders and identifies targets for enhancing QOL through treatment.
\end{abstract}

Keywords Anxiety disorders · Quality of life $\cdot$ Functional impairment $\cdot$ Avoidance $\cdot$ Comorbidity

\section{Introduction}

Anxiety disorders are estimated to have the highest lifetime prevalence rates of all psychiatric disorders (18.0-3.7\%; [1]) and result in considerable functional impairment and economic burden $[2 \bullet, 3,4]$. As a result, anxiety disorders have a significant and detrimental impact on QOL across the lifespan, particularly when left untreated [5, 6].

Quality of life (QOL) refers to a subjective evaluation of life in general and is often represented in the literature through multidimensional measurements of QOL, satisfaction with life, and overall wellbeing. Related to anxiety disorders, QOL has been used to estimate the impact of anxiety on daily functioning, predict long-term consequences of the disorder, and assess the effectiveness of treatment. The large majority of research focuses on health-related QOL,

This article is part of the Topical Collection on Anxiety Disorders

M. Taylor Wilmer

dr.taylor.wilmer@gmail.com

1 Center for Anxiety and Behavioral Change, 1487 Chain Bridge Road, Suite \#203, McLean, VA 22101, USA representing the impact of anxiety on health and health care, and is based on the subjective self-report of the individual. (A review of specific QOL measures is beyond the scope of this paper but can be found in [5].) QOL impairments among anxiety disorders have generally fallen into the following categories: physical health, emotional (or mental) health, occupational or educational functioning, social functioning, home and family functioning, and financial independence [6].

Prior reviews examining QOL among the anxiety disorders have generally focused on disorder-specific impacts and differences between individuals with and without anxiety disorders ([7]). Indeed, individuals with anxiety disorders are robustly shown to report poorer QOL relative to those without an anxiety disorder, regardless of the type of anxiety experienced [6, 7]. Meta-analytic research has further demonstrated that QOL improves significantly following cognitive behavioral therapy (CBT), the gold standard treatment for anxiety disorders [8]. In our current paper, we review recent literature, published within the last 3 years, on QOL in anxiety disorders, with a specific focus on correlates of QOL. Although prior reviews have highlighted the nature of QOL impairments among anxiety disorders, no review has 
yet articulated specific correlates of QOL. Symptom measures have been shown to account for only a small to moderate proportion of variance in QOL scores [9], suggesting that examining additional transdiagnostic factors may shed light on potential mediators and moderators of QOL and lead to enhancements in treatment.

In this article, we review recent research on the correlates of QOL in children, adolescents, and adults with anxiety disorders, including agoraphobia, generalized anxiety disorder (GAD), panic disorder (PD), selective mutism (SM), social anxiety disorder (SAD), and specific phobias (SPs). Rather than focus on diagnostic differences, we adopt a perspective commensurate with the Research Domain Criteria (RDoC) recommendations for assessing fundamental underlying mechanisms of dysfunction that cut across diagnostic categories [10]. We have organized our review into four areas of potential QOL correlates, with a focus on (1) subjective distress, (2) behavioral responses, (3) functional impairment, and (4) clinical factors.

Within subjective distress, we focus on anxiety-related symptoms and sensitivities that may impact QOL, including symptom severity, anxiety sensitivity, distress tolerance, and positive and negative affect. Within behavioral responses, we focus on maladaptive coping behaviors for anxiety that could perpetuate QOL impairments, including anxious avoidance, substance use, and emotion dysregulation. Within functional impairment, we examine the impact of anxiety on social, physical, and occupational functioning as they relate to QOL. Within clinical factors, we concentrate on influences adjacent to anxiety symptoms that may impact QOL, including biopsychosocial factors, comorbidity, treatment response, and longitudinal outcomes. Finally, we include a brief review of the burgeoning area of research into QOL and anxiety during the COVID-19 pandemic. We conclude with considerations for future research and recommendations for treatment based on our review.

\section{Correlates Associated with Subjective Distress}

\section{Symptom Severity}

Symptom severity in anxiety disorders has been linked to greater clinical burden, higher levels of comorbidity, and poorer treatment response [11]. Prior meta-analyses have highlighted the difference in QOL among individuals with clinical levels of anxiety symptoms compared to those without [6]. Recent research reaffirms these findings, documenting the direct effects of symptom severity and diagnostic status on QOL for individuals with anxiety disorders. Specifically, anxiety symptom severity was inversely associated with QOL among adolescents with anxiety [12-14], adults with anxiety [15-21], andolder adults with anxiety [22]. Research within communitybased samplesunderscores the severity of QOL impairments for individuals with moderate tohigh levels of anxiety symptoms (e.g., [14]) and suggests that early intervention couldbe key to preventing severe functional impairment. Remission status alsocorrelated with QOL impairments. QOL was poorer among adults with a currentanxiety disorder compared to those in remission from an anxiety disorder [23], whereas individuals with current andremitted anxiety disorders reported poorer QOL than healthy controls [24].

\section{Anxiety Sensitivity}

Anxiety sensitivity is conceptualized as the fear of somatic symptoms of anxious arousal (e.g., heart palpitations, sweating, shaking) and the belief that these symptoms will have negative consequences [25]. Anxiety sensitivity is a correlate of both anxiety and depressive disorders and is associated with higher levels of disability [25-27]. Prior research has noted that dimensions of anxiety, such as a heightened sensitivity to anxious arousal, have been a better predictor of long-term disability than course trajectories [28] or distress intolerance [29]. Recent research provides preliminary support for anxiety sensitivity as a correlate of QOL in anxiety disorders, revealing that changes in anxiety sensitivity during CBT for anxiety predicted improvements in QOL among individuals with HIV/ AIDS [30]. As an effective though underutilized target for clinical intervention [27], anxiety sensitivity may play a far more significant role in functional impairment and QOL than is currently documented.

\section{Distress Tolerance}

Distress tolerance is considered a transdiagnostic construct associated with the perceived and actual ability to tolerate distress [31]. Individuals low in distress tolerance may find emotional distress highly uncomfortable and seek opportunities to escape. Distress tolerance is associated with lower anxiety symptomatology and higher QOL in prior studies $[32,33]$, and thus could play a role in QOL for individuals with anxiety disorders. Recent research yields preliminary supportive data, finding that distress tolerance mediated the relationship between early childhood neglect and QOL in adulthood for adults with SAD or GAD [34]. However, some studies have noted that distress tolerance may not be predictive of impairment in anxiety disorders once other factors, such as anxiety sensitivity and negative affect, are considered [29]. 


\section{Positive and Negative Affect}

Emotion processing deficits, including heightened negative affect and dampened positive affect, are core components of anxiety and depressive disorders [35], and recent research has shown that they may also impact QOL for individuals with anxiety disorders. Positive affect positively predicted QOL among individuals with GAD, above and beyond negative affect and comorbid depression [36]. Relatedly, increases in positive affect predicted greater QOL improvement from pre- to post-treatment for individuals with SAD, particularly for those who reported low QOL at baseline [37]. Negative affect also moderated the effect of CBT on QOL, such that higher pre-treatment negative affect resulted in less QOL improvement during CBT for individuals with anxiety disorders [38•]. Attention to the affective experience, and particularly emotion regulation processes (see "Emotion Regulation" section below) during CBT may serve to enhance the impact of treatment on QOL for individuals with anxiety disorders.

\section{Correlates Associated with Behavioral Responses}

In an effort to cope with the discomfort of intense anxiety and panic, individuals with anxiety disorders often rely on maladaptive coping behaviors, such as anxious avoidance, substance use, and maladaptive emotion regulation strategies [11]. These behaviors can provide relief in the moment but ultimately maintain or worsen anxiety over time [39]. The extent to which anxious individuals engage in maladaptive coping behaviors, particularly avoidance and safety behaviors, may negatively impact QOL among those with anxiety disorders.

\section{Experiential Avoidance and Safety Behaviors}

Prior research has shown that avoidance behavior was a significant predictor of disability for individuals with anxiety disorders, both concurrently and 4 years later $[26,28]$. Recent research found that greater reliance on avoidant and escape coping correlated with poorer QOL among individuals with neurotic spectrum disorders [17], and experiential avoidance inversely predicted QOL for individuals with PD symptoms [40•]. However, other recent publications yield a contrasting pattern, finding that experiential avoidance of anxiety-provoking stimuli was not a significant correlate of QOL among individuals with anxiety disorders after accounting for positive and negative affect [38•].

Safety behaviors, often considered a form of subtle avoidance for individuals with anxiety disorders, have yielded similarly mixed results. Among a clinical analog sample of individuals with anxiety, greater engagement in safety behaviors and stronger positive beliefs about safety behaviors were associated with lower QOL [41]. Moreover, preventative use of safety behaviors mediated the relationship between anxiety symptom severity and QOL [40•]. However, Butler et al. [42] found no relationship between safety behaviors and QOL among a treatment-seeking sample of individuals with SAD. Given that reducing avoidance is a primary treatment target in CBT, a more nuanced understanding of the relationship between avoidance and QOL may enable CBT to be more impactful for treatment-seeking individuals with anxiety disorders.

\section{Substance Use Behaviors}

Anxiety disorders are highly comorbid with substance use disorders [43], and prior research has shown that individuals with anxiety who regularly use or abuse substances (e.g., alcohol and/or drugs) report lower QOL than those who do not use substances [44, 45]. Even more specifically, Robinson et al. [46] found that individuals with anxiety disorders who use substances to cope with anxiety reported lower QOL than those who do not use substances to cope. However, new research in this area is limited. Only one recent article examined QOL related to substance use in anxiety, finding that individuals with anxiety disorders who used cannabis (but did not meet criteria for cannabis use disorder) reported poorer QOL than non-cannabis users in the areas of mental health and role functioning, but noncannabis users did not differ in QOL compared to those with comorbid cannabis use disorder [47]. Future research should consider substance type, frequency, and purpose of use in understanding substance use behaviors as a correlate of QOL in anxiety disorders.

\section{Emotion Regulation}

As detailed in the "Positive and Negative Affect" section above, the affective experience can impact QOL and treatment outcome for individuals with anxiety disorders. It would follow, then, that difficulties regulating emotion effectively may also correlate with QOL. Indeed, recent research suggests that emotion dysregulation in anxiety may be an important predictor of QOL in anxiety disorders. Among individuals with GAD, less emotion regulation flexibility resulted in poorer QOL and greater emotional distress [48]. Relatedly, decentering (the ability to observe thoughts and feelings as objective events in the mind rather than personally identifying with them) was found to be a moderator of treatment, such that larger increases in decentering predicted greater improvements in QOL following group CBT for 
adults with anxiety disorders [49]. However, when individuals with GAD were treated using emotion regulation therapy (ERT), improvements in emotion regulation via attention allocation were correlated with improved functioning but not improved QOL $[4,50]$. Thus, incorporating emotion regulation, particularly strategies that enhance emotion regulation flexibility, may support QOL improvements among individuals with anxiety disorders.

\section{Correlates Associated with Functional Impairment}

Individuals with anxiety disorders experience significant impairment in functioning in global, social, occupational, and physical domains [4]. Prior research has emphasized the negative impacts of anxiety on various functional domains of life, thereby contributing to poorer QOL overall $[5,6]$. Recent research replicates and extends these findings, highlighting potential diagnostic differences.

\section{Social Functioning}

Individuals with anxiety disorders endorsed greater perceived QOL detriments in the social domain, reporting a smaller social network, fewer social activities, and less social support than non-anxious individuals [51]. As evidenced in prior disorder-specific research [5], SAD showed significant impairments in social-related QOL domains. Notably, individuals with SAD were shown to have the highest functional impairment in the "getting along" disability domain, relative to others with MDD, OCD, and non-clinical national norms [52•].

\section{Physical Health}

QOL detriments in the realm of physical health are often represented by overutilization of medical health services and lower physical activity [5]. Recent research suggests that PD and GAD may result in poorer physical health and, subsequently, poorer QOL. Specifically, individuals with PD or subthreshold panic symptoms were more likely to utilize medical and psychological health services, and endorsed poorer QOL, compared to individuals without panic symptoms [19]. Similarly, adults with GAD endorsed low QOL as well as greater healthcare resource utilization in the past 6 months [21]. Lower physical activity was also found to relate to poorer QOL among individuals with clinical levels of worry such as those found in GAD [53].

\section{Occupational Functioning}

Recent research highlights the impact of anxiety disorders on work-related functioning and, subsequently, QOL. Specifically, employment status was a significant predictor of QOL among individuals with anxiety disorders [17]. Additionally, a network analysis of individuals with GAD demonstrated strong connections between GAD and two areas of QOL: satisfaction with working ability and ability to engage in daily activities [54]. Adults with GAD also demonstrated more impairment in work productivity and activity in addition to lower QOL compared with adults without GAD [21].

\section{Correlates Associated with Clinical Factors}

\section{Biopsychosocial Factors}

Biopsychosocial characteristics are understudied in the area of QOL in anxiety disorders, often serving as control variables rather than key variables of interest. Prior research into these factors has been both limited and mixed. Specifically, early studies found that older age was associated with poorer QOL for individuals with PD [55, 56], but systematic reviews and meta-analyses have shown no effects of age or gender on QOL across anxiety disorders [6,9]. More disorder-relevant variables, such as age of symptom onset, may be more applicable to QOL. For instance, prior research revealed that later age of onset in GAD is associated with poorer QOL, particularly in the domain of physical health, for older adults $[57,58]$. The present literature search did not yield specific findings related to QOL and sociodemographic variables, but recent research did highlight the importance of biological factors. Specifically, a genetic vulnerability to anxiety disorders was negatively correlated with vulnerability to QOL, suggesting that common genetic components may underlie the link between these two constructs [59]. The effects of biological factors on QOL in anxiety warrant further investigation, particularly with current technologies such as neuroimaging, psychophysiology, and blood-based approaches.

\section{Comorbidity}

Comorbidity in anxiety disorders is associated with more severe symptoms, a more chronic course, and greater functional impairment $[11,26,28]$. A large proportion of individuals with an anxiety disorder meet criteria for an additional psychiatric disorder, most often another anxiety disorder (48-68\%) or depressive disorder $(81 \%$; $[1,60])$. Recent research expands on the specific QOL impairments associated with comorbidity in anxiety disorders. Individuals with anxiety disorders who also had comorbid disorder(s) endorsed significantly lower QOL relative to individuals without comorbidity and individuals in remission from anxiety disorders $[2 \bullet, 13,61]$. Within some samples, only individuals with comorbid disorders reported poorer QOL than healthy controls, whereas individuals with a single anxiety disorder did not $[62,63]$. 
Depression comorbidity emerged as a particularly notable correlate with QOL in anxiety disorders. Depression symptoms demonstrated a strong inverse correlation with QOL among individuals with GAD and PD [15, 54]. Among individuals with SAD, only those with comorbid depression or OCD reported greater disability and lower QOL than those without comorbidity [52•]. Related to treatment outcomes, Wilner and colleagues found that the number of comorbid diagnoses - broadly defined - did not predict change in QOL following CBT for anxiety [28]. However, among individuals with comorbid SAD and MDD, participants who were able to achieve MDD remission following pharmacotherapy had significantly better improvements in QOL and functioning than those without MDD remission [64]. Thus, comorbid depression may be especially relevant for QOL outcomes in treatment for anxiety disorders.

\section{Treatment Response}

CBT and pharmacotherapy both yield small to moderate positive effects on QOL outcomes [8, 65]. Recent research has replicated prior findings, confirming that CBT yields decreased symptom severity and improved QOL for children and adults with anxiety disorders [38•, 42, 66-69]. Metaanalytic research strengthens these findings [70•, 71, 72•]. Interestingly, research points to symptom severity as a moderator of treatment type and QOL improvement, such that individuals with greater symptom severity experienced greater QOL improvements following CBT, whereas individuals with lower symptom severity experienced greater QOL improvements following acceptance and commitment therapy (ACT; [73]).

The impact of treatment has also extended to CBT that incorporates virtual reality exposures (VR-CBT), which yielded QOL improvements for individuals with SAD [74] and SP [75, 76], although sample sizes were small. Importantly, recent research has extended these findings to variations of traditional CBT that may increase accessibility to effective treatment. Specifically, internet-delivered CBT (iCBT) for anxiety disorders yielded a moderate effect on QOL, both in single studies [77-80] and meta-analyses [81•, 82]. In contrast, a small non-significant effect was found in a study on iCBT for SAD, PD, and OCD, although sample size was small [83]. Of note, positive treatment outcomes may not be exclusive to CBT. One RCT demonstrated a positive effect of anthroposophic art therapy on reducing symptom severity and improving QOL among women with anxiety [84].

\section{Longitudinal Outcomes}

Epidemiological research indicates that anxiety disorders have a high ratio of 1-year lifetime prevalence, suggesting a chronic recurrent course [11]. Although treatment for anxiety disorders produces moderate QOL improvements, not all individuals respond to these front-line interventions, and those who are treatment refractory exhibit particularly low QOL and increased rates of suicide [85]. Recent research lends additional data to the longitudinal effects of treatment on QOL and the impacts of non-remission.

Unique research has emerged on the very longterm effects of CBT on QOL. An investigation of QOL 12-31 years after individuals with anxiety disorders completed group CBT for PD found that reported QOL was not significantly different from that of the general population [86•]. Likewise, for individuals in remission from anxiety disorders 2-14 years following treatment, QOL remained improved, whereas the majority of individuals who remained symptomatic following treatment reported severely impaired QOL [2•]. However, even for treatment refractory individuals, there may still be hope for improvement. Individuals with SAD who were treatment refractory to medication yielded positive changes in QOL following cognitive therapy, and these gains were maintained at 1-year follow up [69].

\section{QOL and Anxiety During COVID-19}

The COVID-19 pandemic has offered a unique opportunity to observe the relationship between anxiety and QOL. Although publication on the impact of COVID-19 is in its nascent phases, emerging research both reaffirms the relationship between anxiety and QOL and highlights potential correlates, particularly among non-clinical populations. Supporting prior research, anxiety symptom severity was negatively correlated with QOL among individuals under COVID lockdown conditions, with females, older individuals, unemployed individuals, and individuals with or a caretaker for a chronic medical condition experiencing lower levels of QOL [87, 88]. Research during COVID has also highlighted the role of maladaptive coping strategies, such that higher levels of avoidant coping, substance use, and denial as methods to cope with COVID-related anxiety predicted poorer QOL for non-clinical adults [89, 90]. At the same time, higher levels of positive coping predicted better QOL. External factors also played a protective role, such that social and environmental support was negatively predictive of anxiety and positively predictive of QOL [91]. Interestingly, higher levels of pre-COVID QOL acted as a protective factor against anxiety during the pandemic in non-clinical populations [92-94]. It should be noted that the majority of thisresearch utilized concurrent, incentivized, online data collection, andlongitudinal data will lend further strength to these findings. 


\section{Conclusion}

Both prior and current research demonstrates the detrimental effects of anxiety disorders on QOL. Our review, which summarizes research in this area over the past 3 years, is the first to consider specific correlates of QOL in the context of anxiety disorders. Recent literature highlighted factors related to subjective distress, behavioral responses, functional impairment, and behavioral responses. We were most interested by the transdiagnostic correlates that emerged as influential, including anxiety sensitivity, distress tolerance, emotion and emotion regulation, and avoidance. These findings suggest that ways in which individuals with anxiety disorders experience and respond to their emotions are different from non-anxious individuals and may partly explain their reported lower levels of QOL. It may be that the experience of anxiety is heightened, triggering increased distress and negative affect, which anxious individuals then have difficulty downregulating. In an attempt to cope, these individuals avoid or use safety behaviors, which in turn disrupts their occupational, social, and physical functioning.

These transdiagnostic factors offer potential targets for treatment enhancement. The positive impact of CBT, including VR-CBT and iCBT, was confirmed through the recent research summarized here. However, not all individuals respond to $\mathrm{CBT}$, and even those in remission following treatment may still experience poorer QOL than those who have never had an anxiety disorder [24]. Given the nuanced role that many of these correlates play, it seems critical to incorporate a thorough QOL assessment at the beginning of treatment. Future research examining these correlates as components of treatment outcome could further shed light on their role, and treatment that directly targets them (such as ERT to improve emotion regulation, or ACT to reduce experiential avoidance) may help close the QOL gap. Additionally, transdiagnostic treatments, such as the Unified Protocol, which addresses common emotion regulation deficits in emotional disorders to effect symptom change across a broad range of outcomes [71], may lessen the detrimental impact of comorbid depression on QOL.

Finally, preliminary research examining the impact of the COVID-19 pandemic emphasizes the potential protective role of these correlates during a world-wide period of anxiety and stress. Although much research considers the detrimental impact of anxiety on QOL, COVID data showed a unique, if not unsurprising, reverse relationship: higher pre-pandemic QOL mitigated the impact of the pandemic on anxiety. Additionally, positive social functioning and adaptive coping were protective of QOL during this period of stress and uncertainty. Thus, the relationship between QOL and anxiety disorders is bidirectional, and understanding the mediating and moderating mechanisms of this relationship may help us build resilience and improve treatment outcomes for individuals with anxiety disorders.

\section{Compliance with Ethical Standards}

Conflict of Interest The authors declare no competing interests.

\section{References}

Papers of particular interest, published recently, have been highlighted as:

- Of importance

1. Kessler RC, Petukhova M, Sampson NA, Zaslavsky AM, Wittchen HU. Twelve-month and lifetime prevalence and lifetime morbid risk of anxiety and mood disorders in the United States. Int J Methods Psychiatr Res. 2012;21:169-84. https://doi. org/10.1002/mpr.1359.

2. Higgins C, Chambers JA, Major K, Durham RC. Healthcare costs and quality of life associated with the long-term outcome of anxiety disorders. Anxiety Stress Coping 2021;34:228-41. https://doi.org/10.1080/10615806.2020.1839731. This study highlighted the long-term trajectory of comorbidity and symptom remission on QOL in anxiety disorders.

3. Konnopka A, König H. Economic burden of anxiety disorders: a systematic review and meta-analysis. Pharmacoeconomics. 2020;38:25-37. https://doi.org/10.1007/s40273-019-00849-7.

4. McKnight PE, Monfort SS, Kashdan TB, Blalock D v, Calton JM. Anxiety symptoms and functional impairment: a systematic review of the correlation between the two measures. Clin Psychol Rev 2016;45:115-30. https://doi.org/10.1016/j.cpr.2015.10.005.

5. Mendlowicz M v, Stein MB. Quality of life in individuals with anxiety disorders. Am J Psychiatry 2000;157:669-82. https:// doi.org/10.1176/appi.ajp.157.5.669.

6. Olatunji BO, Cisler JM, Tolin DF. Quality of life in the anxiety disorders: a meta-analytic review. Clin Psychol Rev. 2007;27:572-81. https://doi.org/10.1016/j.cpr.2007.01.015.

7. Koury MA, Rapaport MH. Quality of life impairment in anxiety disorders. In: Ritsner MS, Awad AG, editors. Quality of Life Impairment in Schizophrenia. Mood and Anxiety Disorders: Springer; 2007. p. 275-91.

8. Hofmann SG, Wu JQ, Boettcher H. Effect of cognitive-behavioral therapy for anxiety disorders on quality of life: a meta-analysis. J Consult Clin Psychol. 2014;82:375-91. https://doi.org/10.1037/ a0035491.

9. Rapaport MH, Clary C, Fayyad R, Endicott J. Quality-of-life impairment in depressive and anxiety disorders. Am J Psychiatry. $2005 ; 162: 1171-8$.

10. Insel $\mathrm{T}$, Cuthbert B, Garvey M, Heinssen R. Research Domain Criteria (RDoC): toward a new classification framework for research on mental disorders. Am J Psychiatry. 2010;167:748-51.

11. Penninx BWJH, Pine DS, Holmes EA, Reif A. Anxiety disorders. The Lancet. 2021;397:914-27. https://doi.org/10.1016/ s0140-6736(21)00359-7. 
12. Alsamghan AS. Social anxiety symptoms and quality of life of secondary school students of Abha. Saudi Arabia J Genet Psychol. 2021;182:18-30. https://doi.org/10.1080/00221325. 2020.1837065 .

13. Jenkins PE, Ducker I, Gooding R, James M, Rutter-Eley E. Anxiety and depression in a sample of UK college students: a study of prevalence, comorbidity, and quality of life. J Am Coll Health 2020:1-7. https://doi.org/10.1080/07448481.2019.1709474.

14. Raknes S, Pallesen S, Himle JA, Bjaastad JF, Wergeland GJ, Hoffart A, et al. Quality of life in anxious adolescents. Child Adolesc Psychiatry Ment Health. 2017;11:33. https://doi.org/ 10.1186/s13034-017-0173-4.

15. Fidry M, Zugliani MM, do Valle CR, Martins RM, Cabo MCD, Nardi AE, et al. Quality of life in panic disorder: the influence of clinical features and personality traits. Trends Psychiatry Psychother 2019;41:387-93. https://doi.org/10.1590/ 2237-6089-2019-0008.

16. Hempel ME, Taylor JE, Connolly MJ, Alpass FM, Stephens $\mathrm{C}$ v. Scared behind the wheel: what impact does driving anxiety have on the health and well-being of young older adults? Int Psychogeriatr 2017;29:1027-34. https://doi.org/10.1017/ S1041610216002271.

17. Holubova M, Prasko J, Ociskova M, Kantor K, Vanek J, Slepecky $\mathrm{M}$, et al. Quality of life, self-stigma, and coping strategies in patients with neurotic spectrum disorders: a cross-sectional study. Psychol Res Behav Manag. 2019;12:81-95. https://doi.org/10. 2147/PRBM.S179838.

18. Joseph N, Rasheeka VP, Nayar V, Gupta P, Manjeswar MP, Mohandas A. Assessment of determinants and quality of life of university students with social phobias in a coastal city of south India. Asian J Psychiatr. 2018;33:30-7. https://doi.org/10.1016/j. ajp.2018.02.008.

19. Politis S, Bellos S, Hadjulis M, Gournellis R, Petrikis P, Ploumpidis D, et al. Epidemiology of panic disorder and subthreshold panic symptoms in the Greek general population. Psychiatriki. 2020;31:201-15. https://doi.org/10.22365/jpsych. 2020.313.201.

20. Stephens AN, Collette B, Hidalgo-Munoz A, Fort A, Evennou $\mathrm{M}$, Jallais $\mathrm{C}$. The impacts of anxiety over driving on self-reported driving avoidance, work performance and quality of life. J Transp Health. 2020;19: 100929.

21. Yu W, Singh SS, Calhoun S, Zhang H, Zhao X, Yang F. Generalized anxiety disorder in urban China: prevalence, awareness, and disease burden. J Affect Disord. 2018;234:89-96. https://doi.org/ 10.1016/j.jad.2018.02.012.

22. Canuto A, Weber K, Baertschi M, Andreas S, Volkert J, Dehoust $\mathrm{MC}$, et al. Anxiety disorders in old age: psychiatric comorbidities, quality of life, and prevalence according to age, gender, and country. Am J Geriatr Psychiatry. 2018;26:174-85. https://doi. org/10.1016/j.jagp.2017.08.015.

23. Kasteenpohja T, Marttunen M, Aalto-Setala T, Perala J, Saarni SI, Suvisaari J. Outcome of depressive and anxiety disorders among young adults: results from the Longitudinal Finnish Health 2011 Study. Nord J Psychiatry. 2018;72:205-13. https:// doi.org/10.1080/08039488.2017.1418429.

24. Seidl E, Venz J, Ollmann TM, Voss C, Hoyer J, Pieper L, et al. How current and past anxiety disorders affect daily life in adolescents and young adults from the general population-an epidemiological study with ecological momentary assessment. Depress Anxiety. 2021;38:272-85. https://doi.org/10.1002/da.23133.

25. Hovenkamp-Hermelink JHM, van der Veen DC, Oude Voshaar RC, Batelaan NM, Penninx B, Jeronimus BF, et al. Anxiety sensitivity, its stability and longitudinal association with severity of anxiety symptoms. Sci Rep. 2019;9:4314. https://doi.org/10. 1038/s41598-019-39931-7.
26. Hendriks SM, Spijker J, Licht CM, Beekman AT, Hardeveld F, de Graaf R, et al. Disability in anxiety disorders. J Affect Disord. 2014;166:227-33. https://doi.org/10.1016/j.jad.2014.05.006.

27. Keough ME, Schmidt NB. Refinement of a brief anxiety sensitivity reduction intervention. J Consult Clin Psychol. 2012;80:76672. https://doi.org/10.1037/a0027961.

28. Hendriks SM, Spijker J, Licht CM, Hardeveld F, de Graaf R, Batelaan NM, et al. Long-term disability in anxiety disorders. BMC Psychiatry. 2016;16:248. https://doi.org/10.1186/ s12888-016-0946-y.

29. Michel NM, Rowa K, Young L, McCabe RE. Emotional distress tolerance across anxiety disorders. J Anxiety Disord. 2016;40:94-103. https://doi.org/10.1016/j.janxdis.2016.04.009.

30. Paulus DJ, Brandt CP, Lemaire C, Zvolensky MJ. Trajectory of change in anxiety sensitivity in relation to anxiety, depression, and quality of life among persons living with HIV/AIDS following transdiagnostic cognitive-behavioral therapy. Cogn Behav Ther. 2020;49:149-63. https://doi.org/10.1080/16506073.2019. 1621929 .

31. Simons JS, Gaher RM. The Distress Tolerance Scale: development and validation of a self-report measure. Motiv Emot. 2005;29:83-102. https://doi.org/10.1007/s11031-005-7955-3.

32. Bernstein A, Marshall EC, Zvolensky MJ. Multi-method evaluation of distress tolerance measures and construct(s): concurrent relations to mood and anxiety psychopathology and quality of life. J Exp Psychopathol. 2011;2:386-99. https://doi.org/10. 5127/jep.006610.

33. Keough ME, Riccardi CJ, Timpano KR, Mitchell MA, Schmidt NB. Anxiety symptomatology: the association with distress tolerance and anxiety sensitivity. Behav Ther. 2010;41:567-74. https://doi.org/10.1016/j.beth.2010.04.002.

34. Rosencrans PL, Bui E, Rogers AH, Simon NM, Baker AW. Disentangling distress tolerance, emotion regulation, and quality of life in childhood trauma and adult anxiety. Int J Cogn Ther. 2017;10:283-303. https://doi.org/10.1521/ijct.2017.10.4.283.

35. Gross JJ, Jazaieri H. Emotion, emotion regulation, and psychopathology. Clinical Psychological Science. 2014;2:387-401. https://doi.org/10.1177/2167702614536164.

36. Das A, Clerkin EM, Tolin DF, Assaf M, Diefenbach GJ. Moving beyond the negative: contributions of positive and negative affect on quality of life in patients with generalized anxiety disorder. $\mathbf{J}$ Nerv Ment Dis. 2020;208:843-7. https://doi.org/10.1097/NMD. 0000000000001228.

37. Sewart AR, Niles AN, Burklund LJ, Saxbe DE, Lieberman MD, Craske MG. Examining positive and negative affect as outcomes and moderators of cognitive-behavioral therapy and acceptance and commitment therapy for social anxiety disorder. Behav Ther. 2019;50:1112-24. https://doi.org/10.1016/j.beth.2019.07.001.

38. Wilner JG, Dufour S, Kennedy K, Sauer-Zavala S, Boettcher H, Farchione TJ, et al. Quality of life in heterogeneous anxiety disorders: changes across cognitive-behavioral treatments. Behav Modif 2020;44:343-64. https://doi.org/10.1177/0145445518 815603. This article directly examines affect and experiential avoidance as moderators of treatment outcome in CBT.

39. Spinhoven P, van Hemert AM, Penninx B. Experiential avoidance and bordering psychological constructs as predictors of the onset, relapse and maintenance of anxiety disorders: one or many? Cognit Ther Res. 2017;41:867-80. https://doi.org/10. 1007/s10608-017-9856-7.

40.• Kirk A, Meyer JM, Whisman MA, Deacon BJ, Arch JJ. Safety behaviors, experiential avoidance, and anxiety: A path analysis approach. J Anxiety Disord 2019;64:9-15. https://doi.org/ 10.1016/j.janxdis.2019.03.002. This study showed that safety behaviors and experiential avoidance mediated the relationship between symptom severity and quality of life. 
41. Meyer JM, Kirk A, Arch JJ, Kelly PJ, Deacon BJ. Beliefs about safety behaviours in the prediction of safety behaviour use. Behav Cogn Psychother. 2019;47:631-44. https://doi.org/10. 1017/S1352465819000298.

42. Butler RM, O’Day EB, Swee MB, Horenstein A, Heimberg RG. Cognitive behavioral therapy for social anxiety disorder: predictors of treatment outcome in a quasi-naturalistic setting. Behav Ther. 2021;52:465-77. https://doi.org/10.1016/j.beth.2020.06.002.

43. Conway KP, Compton W, Stinson FS, Grant BF. Lifetime Comorbidity of DSM-IV mood and anxiety disorders and specific drug use disorders: results from the national epidemiologic survey on alcohol and related conditions. J Clin Psychiatry. 2006;67:247-57. https://doi.org/10.4088/JCP.v67n0211.

44. Cullen BA, la Flair LN, Storr CL, Green KM, Alvanzo AAH, Mojtabai R, et al. Association of comorbid generalized anxiety disorder and alcohol use disorder symptoms with health-related quality of life: results from the national epidemiological survey on alcohol and related conditions. J Addict Med. 2013;7:394400. https://doi.org/10.1097/ADM.0b013e31829faa1c.

45. Lev-Ran S, le Foll B, McKenzie K, Rehm J. Cannabis use and mental health-related quality of life among individuals with anxiety disorders. J Anxiety Disord. 2012;26:799-810. https:// doi.org/10.1016/j.janxdis.2012.07.002.

46. Robinson JA, Sareen J, Cox BJ, Bolton JM. Correlates of selfmedication for anxiety disorders: Results from the national epidemiolgic survey on alcohol and related conditions. J Nerv Ment Dis. 2009;197:873-8. https://doi.org/10.1097/NMD.0b013e3181c299c2.

47. Feingold D, Rehm J, Factor H, Redler A, Lev-Ran S. Clinical and functional outcomes of cannabis use among individuals with anxiety disorders: a 3-year population-based longitudinal study. Depress Anxiety. 2018;35:490-501. https://doi.org/10.1002/da.22735.

48. Conroy K, Curtiss JE, Barthel AL, Lubin R, Wieman S, Bui E, et al. Emotion regulation flexibility in generalized anxiety disorder. J Psychopathol Behav Assess. 2020;42:93-100. https:// doi.org/10.1007/s10862-019-09773-8.

49. Hayes-Skelton SA, Lee CS. Changes in decentering across cognitive behavioral group therapy for social anxiety disorder. Behav Ther. 2018;49:809-22.

50. Renna ME, Seeley SH, Heimberg RG, Etkin A, Fresco DM, Mennin DS. Increased attention regulation from emotion regulation therapy for generalized anxiety disorder. Cogn Ther Res. 2017;42:121-34. https://doi.org/10.1007/s10608-017-9872-7.

51. Saris IMJ, Aghajani M, van der Werff SJA, van der Wee NJA, Penninx B. Social functioning in patients with depressive and anxiety disorders. Acta Psychiatr Scand. 2017;136:352-61. https://doi.org/10.1111/acps.12774.

52. Park SH, Song YJC, Demetriou EA, Pepper KL, Hickie IB, Glozier N, et al. Distress, quality of life and disability in treatmentseeking young adults with social anxiety disorder. Early Interv Psychiatry 2021;15:57-67. https://doi.org/10.1111/eip. 12910. This study showed the impact of comorbidity on QOL in SAD and highlights the specific influence of comorbid depression.

53. McDowell CP, Gordon BR, MacDonncha C, Herring MP. Physical activity correlates among older adults with probable generalized anxiety disorder: results from The Irish Longitudinal Study on Ageing. Gen Hosp Psychiatry. 2019;59:30-6. https://doi.org/ 10.1016/j.genhosppsych.2019.04.012.

54. Barthel AL, Pinaire MA, Curtiss JE, Baker AW, Brown ML, Hoeppner SS, et al. Anhedonia is central for the association between quality of life, metacognition, sleep, and affective symptoms in generalized anxiety disorder: a complex network analysis. J Affect Disord. 2020;277:1013-21. https://doi.org/10. 1016/j.jad.2020.08.077.

55. Hollifield M, Katon W, Skipper B, Chapman T, Ballenger JC, Mannuzza S, et al. Panic disorder and quality of life: variables predictive of functional impairment. Am J Psychiatry. 1997;154:766-72. https://doi.org/10.1176/ajp.154.6.766.

56. Katerndahl DA, Realini JP. Quality of life and panic-related work disability in subjects with infrequent panic and panic disorder. J Clin Psychiatry. 1997;58:153-8. https://doi.org/10.4088/JCP. v58n0403.

57. le Roux H, Gatz M, Wetherell JL. Age at onset of generalized anxiety disorder in older adults. Am J Geriatr Psychiatry. 2005;13:23-30. https://doi.org/10.1176/appi.ajgp.13.1.23.

58. Chou K-L. Age at onset of generalized anxiety disorder in older adults. Am J Geriatr Psychiatry. 2009;17:455-64. https://doi.org/ 10.1097/JGP.0b013e31818f3a93.

59. Ohi K, Otowa T, Shimada M, Sasaki T, Tanii H. Shared genetic etiology between anxiety disorders and psychiatric and related intermediate phenotypes. Psychol Med. 2020;50:692-704. https://doi.org/10.1017/S003329171900059X.

60. Lamers F, van Oppen P, Comijs HC, Smit JH, Spinhoven P, van Balkom AJ, et al. Comorbidity patterns of anxiety and depressive disorders in a large cohort study: the Netherlands Study of Depression and Anxiety (NESDA). J Clin Psychiatry. 2011;72:341-8. https://doi.org/10.4088/JCP.10m06176blu.

61. McMillan KA, Asmundson GJG, Sareen J. Comorbid PTSD and social anxiety disorder: associations with quality of life and suicide attempts. J Nerv Ment Dis. 2017;205:732-7. https://doi. org/10.1097/nmd.0000000000000704.

62. Preti A, Demontis R, Cossu G, Kalcev G, Cabras F, Moro $\mathrm{MF}$, et al. The lifetime prevalence and impact of generalized anxiety disorders in an epidemiologic Italian National Survey carried out by clinicians by means of semi-structured interviews. BMC Psychiatry. 2021;21:48. https://doi.org/10.1186/ s12888-021-03042-3.

63. Sancassiani F, Romano F, Balestrieri M, Caraci F, di Sciascio G, Drago F, et al. The prevalence of specific phobia by age in an Italian Nationwide Survey: how much does it affect the quality of life? Clin Pract Epidemiol Ment Health. 2019;15:30-7. https:// doi.org/10.2174/1745017901915010030.

64. Steiner AJ, Wright SM, Kuhn T, IsHak WW. Comorbid social phobia and major depressive disorder: the influence of remission from depression on quality of life and functioning. Appl Res Qual Life. 2016;12:719-36. https://doi.org/10.1007/ s11482-016-9485-4.

65. Hofmann SG, Wu JQ, Boettcher H, Sturm J. Effect of pharmacotherapy for anxiety disorders on quality of life: a metaanalysis. Qual Life Res. 2014;23:1141-53. https://doi.org/10. 1007/s11136-013-0573-8.

66. Asnaani A, Benhamou K, Kaczkurkin AN, Turk-Karan E, Foa EB. Beyond the constraints of an RCT: naturalistic treatment outcomes for anxiety-related disorders. Behav Ther. 2020;51:434-46. https://doi.org/10.1016/j.beth.2019.07.007.

67. Herbert JD, Forman EM, Kaye JL, Gershkovich M, Goetter E, Yuen EK, et al. Randomized controlled trial of acceptance and commitment therapy versus traditional cognitive behavior therapy for social anxiety disorder: Symptomatic and behavioral outcomes. J Contextual Behav Sci. 2018;9:88-96. https://doi. org/10.1016/j.jcbs.2018.07.008.

68. Kandasamy P, Girimaji SC, Seshadri SP, Srinath S, Kommu JVS. Favourable short-term course and outcome of pediatric anxiety spectrum disorders: a prospective study from India. Child Adolesc Psychiatry Ment Health. 2019;13:11. https://doi.org/ 10.1186/s13034-019-0272-5.

69. Yoshinaga N, Kubota K, Yoshimura K, Takanashi R, Ishida Y, Iyo $\mathrm{M}$, et al. Long-term effectiveness of cognitive therapy for refractory social anxiety disorder: one-year follow-up of a randomized controlled trial. Psychother Psychosom. 2019;88:244-6. https://doi.org/10.1159/000500108. 
70. Carpenter JK, Andrews LA, Witcraft SM, Powers MB, Smits JAJ, Hofmann SG. Cognitive behavioral therapy for anxiety and related disorders: a meta-analysis of randomized placebocontrolled trials. Depress Anxiety 2018;35:502-14. https://doi. org/10.1002/da.22728. This article is the most recent metaanalysis to demonstrates a moderate effect of treatment on QOL improvements in adults with heterogeneous anxiety disorders.

71. Sakiris N, Berle D. A systematic review and meta-analysis of the Unified Protocol as a transdiagnostic emotion regulation based intervention. Clin Psychol Rev. 2019;72: 101751. https://doi.org/ 10.1016/j.cpr.2019.101751.

72.• Yang L, Zhou X, Pu J, Liu L, Cuijpers P, Zhang Y, et al. Efficacy and acceptability of psychological interventions for social anxiety disorder in children and adolescents: a meta-analysis of randomized controlled trials. Eur Child Adolesc Psychiatry 2019;28:79-89. https://doi.org/10.1007/s00787-018-1189-x. This article is the most recent meta-analysis to demonstrate a moderate effect of treatment on QOL improvements in youth with heterogeneous anxiety disorders.

73. Mesri B, Niles AN, Pittig A, LeBeau RT, Haik E, Craske MG. Public speaking avoidance as a treatment moderator for social anxiety disorder. J Behav Ther Exp Psychiatry. 2017;55:66-72. https://doi.org/10.1016/j.jbtep.2016.11.010.

74. Geraets CNW, Veling W, Witlox M, Staring ABP, Matthijssen S, Cath D. Virtual reality-based cognitive behavioural therapy for patients with generalized social anxiety disorder: a pilot study. Behav Cogn Psychother. 2019;47:745-50. https://doi.org/10. 1017/s1352465819000225.

75. Costa RTD, Carvalho MR, Ribeiro P, Nardi AE. Virtual reality exposure therapy for fear of driving: analysis of clinical characteristics, physiological response, and sense of presence. Braz J Psychiatry. 2018;40:192-9. https://doi.org/10.1590/ 1516-4446-2017-2270.

76. Lindner P, Miloff A, Bergman C, Andersson G, Hamilton W, Carlbring P. Gamified, automated virtual reality exposure therapy for fear of spiders: a single-subject trial under simulated real-world conditions. Front Psychiatry. 2020;11:116. https:// doi.org/10.3389/fpsyt.2020.00116.

77. Berger T, Urech A, Krieger T, Stolz T, Schulz A, Vincent A, et al. Effects of a transdiagnostic unguided Internet intervention ('velibra') for anxiety disorders in primary care: results of a randomized controlled trial. Psychol Med. 2017;47:67-80. https:// doi.org/10.1017/s0033291716002270.

78. Boettcher J, Magnusson K, Marklund A, Berglund E, Blomdahl $\mathrm{R}$, Braun U, et al. Adding a smartphone app to internet-based self-help for social anxiety: a randomized controlled trial. Comput Hum Behav. 2018;87:98-108. https://doi.org/10.1016/j.chb. 2018.04.052.

79. Eustis EH, Hayes-Skelton SA, Orsillo SM, Roemer L. Surviving and thriving during stress: a randomized clinical trial comparing a brief web-based therapist-assisted acceptance-based behavioral intervention versus waitlist control for college students. Behav Ther. 2018;49:889-903. https://doi.org/10.1016/j.beth.2018.05.009.

80. Gershkovich M, Herbert JD, Forman EM, Schumacher LM, Fischer LE. Internet-delivered acceptance-based cognitivebehavioral intervention for social anxiety disorder with and without therapist support: a randomized trial. Behav Modif. 2017;41:583-608. https://doi.org/10.1177/0145445517694457.

81. Domhardt M, Letsch J, Kybelka J, Koenigbauer J, Doebler P, Baumeister $\mathrm{H}$. Are Internet- and mobile-based interventions effective in adults with diagnosed panic disorder and/or agoraphobia? A systematic review and meta-analysis. J Affect Disord 2020;276:169-82. https://doi.org/10.1016/j.jad.2020.06.
059. This article is the most recent meta-analysis to show a moderate effect of iCBT on QOL improvements in anxiety disorders.

82. Pasarelu CR, Andersson G, Bergman Nordgren L, Dobrean A Internet-delivered transdiagnostic and tailored cognitive behavioral therapy for anxiety and depression: a systematic review and meta-analysis of randomized controlled trials. Cogn Behav Ther. 2017;46:1-28. https://doi.org/10.1080/16506073.2016.1231219.

83. Matsumoto K, Sutoh C, Asano K, Seki Y, Urao Y, Yokoo M, et al. Internet-based cognitive behavioral therapy with real-time therapist support via videoconference for patients with obsessivecompulsive disorder, panic disorder, and social anxiety disorder: pilot single-arm trial. J Med Internet Res. 2018;20: e12091. https://doi.org/10.2196/12091.

84. Abbing A, Baars EW, de Sonneville L, Ponstein AS, Swaab H. The effectiveness of art therapy for anxiety in adult women: a randomized controlled trial. Front Psychol. 2019;10:1203. https://doi.org/10.3389/fpsyg.2019.01203.

85. Bystritsky A. Treatment-resistant anxiety disorders. Mol Psychiatry. 2006;11:805-14. https://doi.org/10.1038/sj.mp.4001852.

86. Bilet T, Olsen T, Andersen JR, Martinsen EW. Cognitive behavioral group therapy for panic disorder in a general clinical setting: a prospective cohort study with 12 to 31 -years follow-up. BMC Psychiatry 2020;20:259. https://doi.org/10.1186/s12888020-02679-w. This study highlighted the longterm outcomes up to 31 years following treatment for QOL in anxiety disorders.

87. Ferreira LN, Pereira LN, da Fe BM, Ilchuk K. Quality of life under the COVID-19 quarantine. Qual Life Res. 2021;30:1389405. https://doi.org/10.1007/s11136-020-02724-x.

88. Ozturk Copur E, Karasu F. The impact of the COVID-19 pandemic on the quality of life and depression, anxiety, and stress levels of individuals above the age of eighteen. Perspect Psychiatr Care. 2021. https://doi.org/10.1111/ppc.12730.

89. Rasskazova EI, Leontiev DA, Lebedeva AA. Pandemic as a challenge to subjective well-being: anxiety and coping. Counseling Psychology and Psychotherapy. 2020;28:90-108. https://doi.org/ 10.17759/cpp.2020280205.

90. Shamblaw AL, Rumas RL, Best MW. Coping during the COVID-19 pandemic: relations with mental health and quality of life. Can Psychol. 2021;62:92-100. https://doi.org/10.1037/ cap0000263.

91. Liu C, Lee YC, Lin YL, Yang SY. Factors associated with anxiety and quality of life of the Wuhan populace during the COVID19 pandemic. Stress Health. 2021. https://doi.org/10.1002/smi. 3040.

92. Leong Bin Abdullah MFI, Ahmad Yusof H, Mohd Shariff N, Hami R, Nisman NF, Law KS. Depression and anxiety in the Malaysian urban population and their association with demographic characteristics, quality of life, and the emergence of the COVID-19 pandemic. Curr Psychol 2021:1-12. https://doi.org/ 10.1007/s12144-021-01492-2.

93. Nogueira J, Gerardo B, Silva AR, Pinto P, Barbosa R, Soares S, et al. Effects of restraining measures due to COVID-19: pre- and post-lockdown cognitive status and mental health. Curr Psychol 2021:1-10. https://doi.org/10.1007/s12144-021-01747-y.

94. Siew SKH, Mahendran R, Yu J. Directional effects of social isolation and quality of life on anxiety levels among communitydwelling older adults during a COVID-19 lockdown. Am J Geriatr Psychiatry. 2021. https://doi.org/10.1016/j.jagp.2021.03.012.

Publisher's Note Springer Nature remains neutral with regard to jurisdictional claims in published maps and institutional affiliations. 